\title{
Steroid resistant nephrotic syndrome in children: Clinical presentation, renal histology, complications, treatment and outcome at Bangabandhu Sheikh Mujib Medical University, Dhaka, Bangladesh
}

\author{
Roy RR ${ }^{1}$, Haque $\mathrm{SMS}^{2}$, MamunAA ${ }^{3}$, MuinuddinG ${ }^{4}, \mathrm{Rahman} \mathrm{MH}^{5}$
}

\begin{abstract}
Steroid resistant nephrotic syndrome (SRNS) remains a challenge for pediatric nephrologists. The underlying histopathology usually affects the course of the disease and the response to treatment. This study was designed to determine clinical presentation, renal histology, complications, treatment and outcome in children presenting with SRNS. A prospective analysis was carried out among 32 steroid resistant nephrotic syndrome patients aged 1-18 year in the department of pediatric nephrology, Bangabandhu Sheikh Mujib Medical University, Dhaka, Bangladesh during the period of January 2011 to June 2014. Percutaneous renal biopsy were done in all patients. The histopathology slides were reviewed by competent pathologists. Patients with congenital nephrotic syndrome and nephrotic syndrome secondary to systemic diseases were excluded from the study. Thirty two children fulfilled the inclusion criteria, and included 19 boys and 13 girls, male to female ratio was 1.4:1. Their mean age of presentation was 9.2 year (range 16 month to 16 year). Nine patient(28.22) presented with typical presentation and 23 (71.88\%) presented with atypical presentation which included hematuria (62.5\%), very high cholesterol (>500mg/dl), persistent hypertension (40.63\%), unfavorable age (28.13\%), hypocomplementemia (21.88\%) and azotemia. None had a positive family history or hepatitis B surface antigen. The renal histopathology was compatible with mesengioproliferative glomerulonephritis (MesPGN) in 40.63\%\% (n=17), membranoproliferative glomerulonephritis (MPGN) 21.88\% ( $n=07)$, minimal change disease (MCD) $18.75 \%(n=06)$, focal and segmental glomerulosclerosis (FSGS) in $12.5 \%(n=4)$ and inadequate tissue was found in two cases. All patients were treated by intravenous methylprednisolone four to six pulses along with intravenous cyclophosphamide followed by oral prednisolone. Cyclosporine was added in patients who failed to achieve remission The outcome with steroid and cyclophosphamide-based treatment for iSRNS was further enhanced with addition of ACE inhibitor. Regarding outcome 21(65.63\%) patient responded, five (15.63\%) patients died, four (12.5\%) reached end stage renal disease and two refused to take any treatment. This study revealed that MesPGN was the commonest histopathology in children presented with SRNS, IV methylprednisolone and IV cyclophosphamide are still agood option for treatment of SRNS with a response rate of sixty five percent.
\end{abstract}

KEY WORD: Management, Nephrotic syndrome, Outcome

\section{INTRODUCTION}

Idiopathic steroid resistant nephrotic syndrome (ISRNS) of children can be defined as; a child with nephrotic syndrome who fails to show a complete remission of symptoms after using the full prescribed steroid treatment.The usual steroid protocol used in these cases comprises of prednisone $60 \mathrm{mg} / \mathrm{m} 2 /$ day for six weeks, followed by $40 \mathrm{mg} / \mathrm{m} 2 / 48$ hours for another six weeks ${ }^{1}$. The steroid resistance can be grouped into primary resistance in which there is failure of complete remission after treatment during the first time of nephrotic syndrome presentation, while in the secondary resistance the child initially responds well to steroid regimen for a period of time, after which he shows recurrence of symptoms and failure of complete response to steroid treatment ${ }^{2}$. SRNS is a common problem in pediatric nephrology practice and one that poses significant therapeutic challenge for pediatric nephrologists ${ }^{3,4,5,6}$. The children with SRNS tend to progress to end-stage renal disease (ESRD) due to the progressive damage of the glomerular filtration barrier (GFB) ${ }^{7,8,9,10}$.

Reported rates of steroid resistance among the biopsy series vary from 10 to $20 \%$ in different studies ${ }^{11}$. The underlying histopathology usually affects the course of the disease as well as the response to treatment ${ }^{12,13}$. Results of studies by the International Study of Kidney Disease in Children (ISKDC) revealed focal and segmental glomerulosclerosis (FSGS), mesangial proliferative glomerulonephritis (MesPGN) and minimal change disease (MCD) as the respective morphologic lesions seen in 70\%, 44\% and 7\% of children with SRNS $^{1}$. It is an entity that is difficult to manage. Without treatment, progression to pre-terminal chronic renal failure $(\mathrm{CRF})$ or end-stage renal disease (ESRD), few years after diagnosis, is very high. Different aggressive and potentially toxic treatment regimens have been tried to forestall disease progression, with varied outcome e $^{14-19}$. Partial remission of massive proteinuria is considered as better outcome than no remission ${ }^{15}$. 
Outcome of treatment is quite variable. In good number of patients outcome is guarded. Fifty percent of steroid resistant nephrotic syndrome may progress to end stage renal disease (ESRD) within 5 years of diagnosis ${ }^{20,21}$. This article is intended to highlight the clinical presentation, complication, renal histological pattern and treatment modalities applied and outcome of the patients suffered from SRNS in a tertiary center of Bangladesh.

\section{II .MATERIAL AND METHODS}

This is a prospective observational study, carried out among 32 patients suffering from steroid resistant nephrotic syndrome, aged 1-18 years admitted in the department of pediatric nephrology, Bangabandhu Sheikh Mujib Medical University (BSMMU), Shahbag, Dhaka, Bangladesh during the period of January 2011 to May 2014. Percutaneous renal biopsy was done in all SRNS patients to see the histological pattern, for management purpose and to know the prognosis. The light microscopic and immunohistochemistry slides were reviewed for confirmation of the diagnosis. Certain glomerular and tubulointerstitial changes were interestingly focused for the histological patterns. Glomeruli were counted and examined for the number with global and segmental sclerosis, the number of crescents, the presence or absence of hypercellularity and the type of the infiltrating cells and endocapillary proliferation. The results were expressed quantitatively by counting the total number of glomeruli and calculated the percentage of the affected ones. Tubulointerstitial changes were examined for the presence of tubular atrophy, tubulitis, interstitial fibrosis and interstitial inflammation. The ratio of the affected tubulointerstitium was calculated and presented.

Following were the inclusion and exclusion criteria-

\subsection{Inclusion criteria}

All children aged 1-18 year with steroid resistant nephrotic syndrome.

\subsection{Exclusion criteria}

1. Children with idiopathic steroid sensitive nephrotic syndrome

2. Children with congenital nephrotic syndrome

3. Nephrotic syndrome secondary to systemic diseases

\subsection{Following working definition were used}

Nephrotic Syndrome (NS): It is defined as massive proteinuria (>1 g/ $\mathrm{m}^{2} / 24$ hours), hypoalbuminemia (serum albumin $<2.5 \mathrm{~g} / \mathrm{dl}$ ), hyperlipidemia ( cholesterol $>250 \mathrm{mg} / \mathrm{dl}$ ), \& generalized edema ${ }^{1}$.Remission: Protein free urine (urine protein negative or trace or $<4 \mathrm{mg} / \mathrm{m}^{2} / \mathrm{h}$ ) for 3 consecutive days ${ }^{1}$.Relapse: Massive Proteinuria ( urine protein $3+$ or more) for 3 consecutive days ${ }^{1}$.Steroid Resistant Nephrotic Syndrome (SRNS) : No remission after 6 weeks of standard prednisolone therapy at $60 \mathrm{mg} / \mathrm{kg} / \mathrm{m}^{2} / \mathrm{day}$ will be defined as steroid resistant nephrotic syndrome ${ }^{1}$. Atypical presentation: Nephrotic syndrome patient with age less than 1 yearor more than 10 years, persistent hypertension, persistent hematuria, impaired renal function, high cholesterol (>500mg/dl), hypocomplementemia (low serum C3 or C4), extrarenal features like prolonged fever, arthritis, rash and positive family history.Typical presentation: Nephrotic syndrome patient with no hypertension, no hematuria, normal complement level( normal C3or C4 level), normal renal function, age and less than 2 years and more than 10 years were considered as typical presentation. Following investigations were done Urine for routine and microscopic examination, culture and sensitivity with colony count, 24 hours urinary total protein or spot urinary protein creatinine ratio, serum albumin, lipid profile, serum creatinine, complete blood count (CBC), X-ray chest (CXR), calcium, serum electrolytes, ASO titer, USG of KUB. To exclude secondary cause following investigations were done: monteux test (MT)/Gene expert, C3, C4, HBsAg, Anti HCV, ANA, Anti- ds -DNA, ANCA. Renal biopsy was done in all steroid resistant nephrotic syndrome patients. In relapse cases- infection screening and biochemical status of relapse was seen such as urine for routine and microscopic examination with culture and sensitivity with colony count, spot urinary proteincreatinine ratio, CBC, CXR, S. Albumin and S. Creatinine.

\section{III.RESULTS}

Total number of steroid resistant nephrotic syndrome patients were 32 during January 2011 to may 2014, age range from 16 month to 16 years, mean age 9.2 and median age 10 year, male was 19 and female was 13 (M: $\mathrm{F}=1.4: 1$ ).Nine patients presented with typical presentation, 23 patient presented with atypical presentation. Most of the patients came from low socio-economic background. Renal biopsy was done in all SRNS cases and minimum complications were observed. Microscopic hematuria occured in most of the patients which persist for 6 to 12 hours, gross hematuria in 3 patients, renal hematoma in 2 patients, mild pain in all patients, oozing from puncture site in one patient, one patient needed blood transfusion, transient hypertension 
in 5 patients. All biopsy complications were improved with conservative treatment. Renal histological findings showed messengial proliferative glomerulonephritis( Mes PGN ) in 13 patients, membranoproliferative glomerulonephritis (MPGN) in 7 patients, minimal change disease (MCD) in 6 patients, focal segmental glomerulonephritis (FSGS) in 4 patients, inadequate tissue in 2 patients, all patient were treated with inj. Methylprednisolone and inj. Cyclophosphamide. Cyclosporine was given to one patient and one patient was treated with Mycophenolate mofetil followed by oral prednisolone along with other supportive management. Disease complication included chronic kidney disease (CKD) in 4 patients, infection were found in 20 patients, hypovolumia in 8 patients, failure to thrive in 6 patients. Treatment complications included steroid toxicity in 20 patients, hypertension in 8 patients. 21 patients responded with treatment, end stage renal disease (ESRD) found in 4 patients. Five patients died due complications and 2 patients refused to take treatment. Sixty two percent of our study patient has persistent hematuria, $40 \%$ had persistent hypertension and unfavorable age in $28 \%$.

Table 1: Base line demography of patients

\begin{tabular}{|l|l|}
\hline \multicolumn{1}{|c|}{ Age } & Range 16 month to 16 year \\
\hline Mean age & 9.2 year \\
\hline Median age & 10 year \\
\hline Sex & \\
\hline Male & 19 \\
\hline Female & 13 \\
\hline
\end{tabular}

- Table 1 showing mean age of ourstudy subjects was 9.2 years,median age 10 years,male female ratio 1.4: 1 .

Table 2: Typical presentation in 9 of $32(28.13 \%)$

\begin{tabular}{|l|l|}
\hline presentation & Percentage(\%) \\
\hline Massive proteinuria & 100 \\
\hline Edema & 100 \\
\hline Infection & 70 \\
\hline
\end{tabular}

- Typical presentation found in $28 \%$ of patients, infection was found in $70 \%$.

Table: 3: Atypical presentation in 23 of 32 (71.88 \%)

\begin{tabular}{|l|c|}
\hline Presentation & Percentage(\%) \\
\hline Hematuria ( microscopic-17,macroscopic-3) & $20(62.5 \%)$ \\
\hline High cholesterol(>500mg/dl) & $17(53.13 \%)$ \\
\hline Persistent hypertension & $13(46.3 \%)$ \\
\hline Unfavorable age & $9(28.13 \%)$ \\
\hline Hypocomplementemia & $7(21.88 \%)$ \\
\hline Azotemia & $5(15.63 \%)$ \\
\hline Extrarenal feature/ +ve family history & 0 \\
\hline
\end{tabular}

- Atypical presentations was found in $71.88 \%$

Table 4: Renal histology of SRNS

\begin{tabular}{|l|c|}
\hline Histology & Number (\%) \\
\hline $\begin{array}{l}\text { Mesengial proliferative glomerulonephritis(Mes } \\
\text { PGN) }\end{array}$ & $13(40.63 \%)$ \\
\hline $\begin{array}{l}\text { Membranoproliferative } \\
\text { glomerulonephritis(MPGN) }\end{array}$ & $07(21.88 \%)$ \\
\hline Minimal change disease(MCD) & $06(18.75 \%)$ \\
\hline Focal segmental glomerulonephritis(FSGS) & $04(12.5 \%)$ \\
\hline Inadequate tissue & $02(6.25 \%)$ \\
\hline
\end{tabular}

- Renal biopsy was done in all SRNS patients and among them Mes PGN 40.63\%, MPGN 21.88\%, MCD $18.75 \%$, FSGS $12.5 \%$, inadequate tissue $6.25 \%$ was found. 
Table 5: Complications of renal biopsy

\begin{tabular}{|c|c|c|}
\hline Mild pain & 32 & $\mathbf{1 0 0 \%}$ \\
\hline Hematuria & 32 & $100 \%$ \\
\hline Transient hypertension & 5 & $15.6 \%$ \\
\hline Renal hematoma & 2 & $6.25 \%$ \\
\hline Blood transfusion & 2 & $6.25 \%$ \\
\hline Urinary tract infection & 1 & $3.1 \%$ \\
\hline Oozing from puncture site & 1 & $3.1 \%$ \\
\hline
\end{tabular}

Table: 6: Specific treatment of SRNS

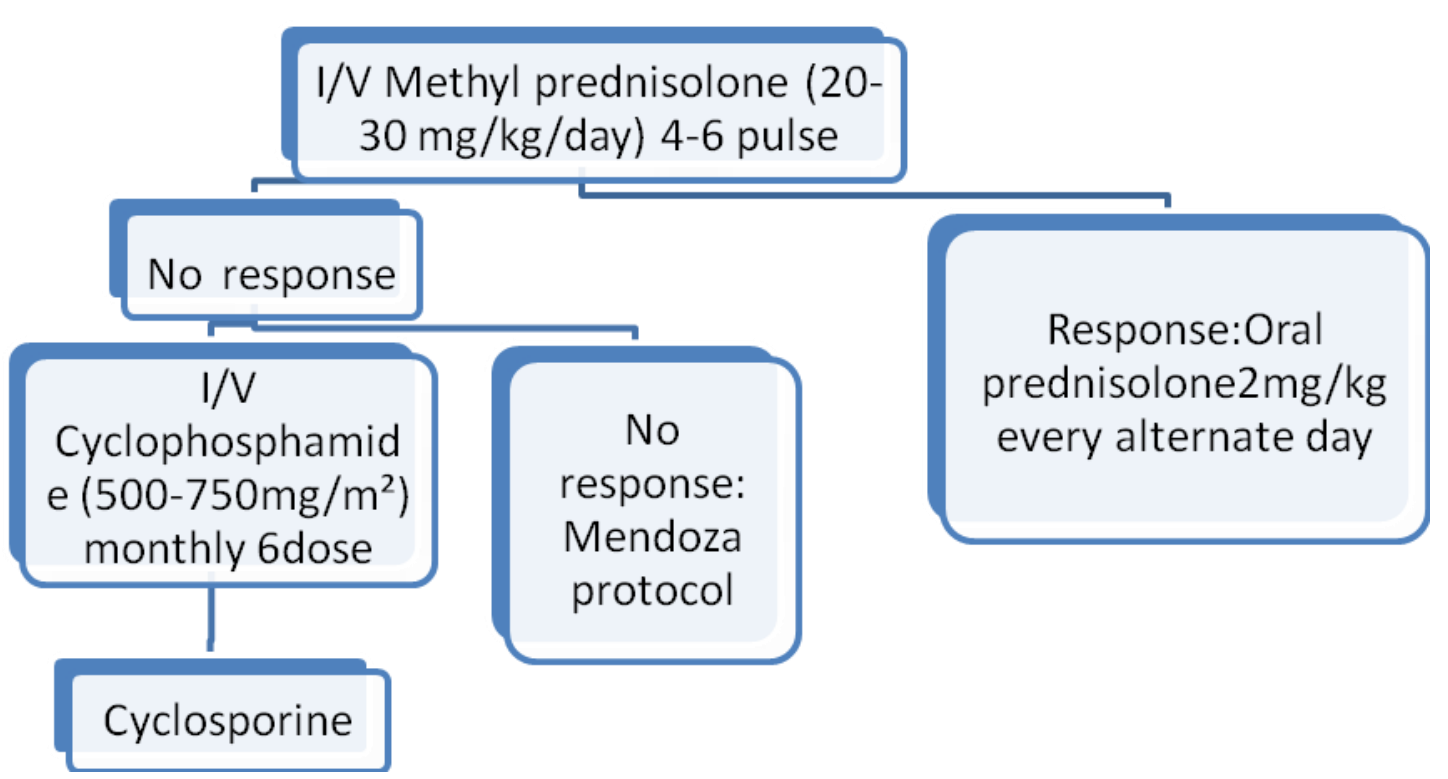

Chart 1: $\quad$ Algorithm for management of SRNS,KIDIGO 2012

Table 7: $\quad$ Outcome of SRNS

\begin{tabular}{|l|l|}
\hline Outcome & Number $(\%)$ \\
\hline Response & $21(65.63 \%)$ \\
\hline Death & $05(15.63 \%)$ \\
\hline Refuse to take treatment & $02(6.25 \%)$ \\
\hline End stage renal disease (ESR & $04(12.5 \%)$ \\
\hline
\end{tabular}

\section{IV.DISCUSSION}

Idiopathic nephrotic syndrome is one of the commonly glomerular diseases in children. Most patients are steroid sensitive and respond to the therapy with complete remission of proteinuria. Approximately 10-20\% of children withnephrotic syndrome who do not completely respond to corticosteroid by 6 weeks were qualified as steroid resistant ${ }^{11}$. Compared to steroid sensitive nephrotic syndrome (SSNS), SRNS is an uncommon clinical entity. 
Table 8: Comparison of glomerular morphologic patterns in other studies with the current study:

\begin{tabular}{|c|c|c|c|c|c|c|c|c|c|}
\hline & \multicolumn{9}{|c|}{ Authors (year)/Country } \\
\hline $\begin{array}{l}\text { Glomerular } \\
\text { morphology }\end{array}$ & $\begin{array}{l}\text { Bhimma } \\
\text { et alb } \\
(1997) / \mathrm{S} \\
\text { outh } \\
\text { Africa22 }\end{array}$ & $\begin{array}{l}\text { Mantan et } \\
\text { al } \\
(2008) / \text { Indi } \\
\text { a23 }\end{array}$ & $\begin{array}{l}\text { Plank et al } \\
(2008) / G e r m a \\
\text { ny } \\
\text { and Austria24 }\end{array}$ & $\begin{array}{l}\text { Asinob } \\
\text { i et } \\
\text { al } \\
(1999) / \\
\text { Nigeria } \\
25\end{array}$ & $\begin{array}{l}\text { Gulati } \\
\text { et } \\
\text { al } \\
(2006) / \\
\text { India1 } \\
2\end{array}$ & $\begin{array}{l}\text { Bonilla } \\
\text {-Felix } \\
\text { et al } \\
\text { (1999) } \\
\text { /USA }\end{array}$ & $\begin{array}{l}\text { Niaudet } \\
(1994) / \\
\text { France26 }\end{array}$ & $\begin{array}{l}\text { ISKD } \\
\text { C } \\
\text { study } \\
(1978) \\
27\end{array}$ & $\begin{array}{l}\text { This } \\
\text { study }\end{array}$ \\
\hline MCD & $13.5 \%$ & $49 \%$ & $31.3 \%$ & $9.8 \%$ & $17.6 \%$ & $35 \%$ & $69.2 \%$ & $76.4 \%$ & $\begin{array}{l}18.75 \\
\%\end{array}$ \\
\hline MPGN & $5.1 \%$ & - & - & $51.2 \%$ & $1.6 \%$ & $5 \%$ & - & $7.5 \%$ & $\begin{array}{l}21.88 \\
\%\end{array}$ \\
\hline FSGS & $28.4 \%$ & $28.6 \%$ & $65.6 \%$ & $4.9 \%$ & $58.8 \%$ & $31 \%$ & $30.8 \%$ & $6.9 \%$ & $\begin{array}{l}12.5 \\
\%\end{array}$ \\
\hline MesPGN & $7.2 \%$ & $22.4 \%$ & $3.1 \%$ & - & $17.6 \%$ & $25 \%$ & - & $2.3 \%$ & $\begin{array}{l}40.63 \\
\%\end{array}$ \\
\hline $\mathrm{MN}$ & $5.5 \%$ & - & - & $9.8 \%$ & $4.4 \%$ & - & - & $1.5 \%$ & - \\
\hline Others & $40.3 \%$ & - & - & $24.3 \%$ & - & $4 \%$ & - & $5.4 \%$ & $\begin{array}{l}6.25 \\
\% \\
\end{array}$ \\
\hline
\end{tabular}

MCD: Minimal change disease, MPGN, Membranoproliferative glomerulonephritis, FSGS, Focal segmental glomerulosclerosis, MesPGN: Mesangial proliferative glomerulonephritis, MN: Membranous nephropathy, bData are for black South African children, ISKDC, International Study of Kidney Disease in Children; data modified to conform to this tabulationMean age of presentation was 9.2 year which meant SRNS is common in higher age group. The mean age at onset of the SRNS in this and other studies Appeared to be a function of the glomerular morphologic lesion as children with MCD-associated SRNS tend to be younger (2.25.1 years) $4{ }^{12,23,24,25}$ than those with non-MCD-associated SRNS who are older (6.2-8.72 years) ${ }^{26-29}$. Hypertension and hematuria are common features of non-MCD. Macroscopic hematuria is rare (3\%), while microscopic hematuria is far more common (32\%). Current study showed macroscopic hematuria $9.3 \%$ and microscopic hematuria 53.13\% which is similar to these studies. All these abnormal features were due to the high prevalence of MesGN and MPGN. Certainly, these are aggressive morphologic variants requiring more aggressive, potentially toxic and expensive combination therapy. The pattern of glomerular lesion seen in this study varied with what is seen in other studies (Table: 8). Children with MPGN have an unfavorable prognosis and develop ESRD during late childhood or early adolescence ${ }^{26}$. MesPGN was the cause of SRNS in $40.63 \%$ in the current study. This is higher to the report by Ejaz et al from Lahore who reported MesPGN as the underlying histopathology in $12 \%$ of theirSRNS patients ${ }^{30}$. The prevalence of MesPGN varies from study to study, some studies have reported higher prevalence rates also. MesPGN has been reported as a cause of SRNS as well as steroid sensitive nephrotic syndrome (SSNS) with a troublesome management protocol $^{31}$.

In the current study most of the patients were treated with $\mathrm{I} / \mathrm{V}$ methylprednisolone along with $\mathrm{I} / \mathrm{V}$ cyclophosphamide followed by oral prednisolone. Calcinurin inhibitor was also used in one patient with steroid and one patient was treated with MMF after failing to achieve remission. With the above mentioned treatment $21(65.63 \%)$ achieved response which was similar to many other studies as different author found different levels of remission ranging from 14.8-80\% depending upon various protocol ${ }^{11}$. Mantan et al ${ }^{23}$ and Harri et al ${ }^{32}$ respectively achieved $47.8 \%$ and $35.1 \%$ remission rate using i.v. dexamethasone and oral cyclophosphamide and prednisolone. Bajpai et al ${ }^{33}$ achieved $29.2 \%$ remission after six months of monthly pulse i.v. cyclophosphamide and alternate day oral prednisolone in SRNS following failure of eight weeks of daily prednisolone and i.v. pulse doses of dexamethasone. However, with the addition of either Angiotensin converting enzyme ( ACE) inhibitor or receptor blocker may contributed a little in those patients who were hypertensive. Four patient (12.5\%) from current study reached ESRD which is not very unusual in case of SRNS and one of these 4 patient had successful renal transplant doing well, rest 3 shifted to maintenance hemodialysis. 


\section{V.CONCLUSION}

MesPGN was the commonest underlying histopathology in children who presented with SRNS to our institution.MPGN, MCD and FSGS were the other histologic variant in this study. Intravenous methylprednisolone with I/V cyclophosphamide combination is still a good choice of combination in SRNS with a remission rate of almost sixth five percent.

\section{REFERENCES}

[1]. Bagga A. Srivastava RN Nephrotic syndrome.In: Srivastava RN. Bagga A (eds). Pediatric Nephrology. $5^{\text {th }}$ edition.Joypee Brothers Medical Publishers Ltd. New Delhi. 110002. 2011. 195-234.

[2]. Gargah T, Labessi A, Goucha- Louzir R, Ben Moussa F, Lakhoua MR. Histopathological spectrum of childhood idiopathic steroid-resistant nephrotic syndrome in Tunisia. Tunis Med.2011; 89(3):258-6.

[3]. Ehrich J. H., Geerlings C, Zivicnjak M., Franke D., Geerlings H., and Gellermann J., Steroid-resistant idiopathic childhood nephrosis: overdiagnosed and undertreated. Nephrology Dialysis Transplantation. 2007; 22: 2183-2193.

[4]. Indian Society of Pediatric Nephrology, Management of steroid resistant nephrotic syndrome. Indian Pediatrics. 2009; 46: 35-47.

[5]. Hamasaki Y., Yoshikawa N. and Hattori S. Cyclosporine and steroid therapy in children with steroidresistant nephrotic syndrome. Pediatric Nephrology. 2009; 24: 2177-2185.

[6]. Habashy D., Hodson E. M., and Craig J. C. Interventions for steroid-resistant nephrotic syndrome: a systematic review. Pediatric Nephrology. 2003; 18:906-912.

[7]. Cattran D. C., Alexopoulos E., Heering P. Cyclosporin in idiopathic glomerular disease associated with the nephrotic syndrome: workshop recommendations. Kidney International. 2007; 72: 1429-1447.

[8]. Mekahli D., Liutkus A., Ranchin B. Long-termoutcome of idiopathic steroid-resistant nephrotic syndrome: a multicenter study. Pediatric Nephrology. 2009; 24: 1525-1532.

[9]. Kitiyakara C., Kopp J. B., and P. Eggers. Trends in the epidemiology of focal segmental glomerulosclerosis. Seminars in Nephrology. 2003; 23: 172-182.

[10]. El-Reshaid K., Kapoor M., Nampoory N., Madda J., Jawad N., and K. Johny. Treatment of children with steroid refractory idiopathic nephrotic syndrome: the Kuwaiti experience. Renal Failure, 1999; 21: 487-494.

[11]. Olowu WA, Adelusola KA, Adefehiniti O. Childhood idiopathic steroid resistant nephrotic syndrome in Souwestern Nigeria. Saudi J kidney Dis Transpl. 2010; 21(5):979-90.

[12]. Gulati S, Sengupta D, Sharma RK, et al. Steroid resistant nephrotic syndrome: role of histo- pathology. Indian Pediatr. 2006; 43(1):55-60.

[13]. Kirpekar R, Yorgin PD, Tune BM, Kim MK, Sibley RK. Clinicopathologic correlates predict the outcome in children with steroid-resistant idiopathic nephrotic syndrome treated with pulse methylprednisolone therapy. Am J Kidney Dis. 2002; 39(6):1143-52.

[14]. Bagga A, Mudigoudar BD, Hari P, Vasudev V. Enalapril dosage in steroid- resistant nephrotic syndrome. Pediatr Nephrol 2004; 19:45-50.

[15]. Cattran DC, Wang MM, Appel G, Matalon A, Briggs W. Mycophenolate mofetil in the treatment of focal segmental glomerulosclerosis. Clin Nephrol 2004;62:405-11.

[16]. Bhimma R, Adhikari M, Asharam K, Connolly C. Management of steroid-resistant focal segmental glomerulosclerosis in children using tacrolimus. Am J Nephrol 2006;26:544-51.

[17]. Bagga A, Sinha A, Moudgil A. Rituximab in patients with the steroid-resistant nephrotic syndrome. $N$ Engl J Med 2007;356:2751-2.

[18]. Ruf RG, Lichtenberger A, Karle SM. Patients with mutations in NPHS2 (podocin) do not respond to standard steroid treatment of nephrotic syndrome. J Am Soc Nephrol 2004; 15:722-32

[19]. 19.Ehrich JH, Geerlings C, Zivicnjak M, Franke D, Geerlings H, Gellermann J. Steroid-resistant idiopathic childhood nephrosis: overdiagnosed and undertreated. Nephrol Dial Transplant 2007;22:2183-93.

[20]. Abrantes MM, Cardoso LS,Lima EM, Penido Silva JM, Diniz JS Bambirra EA, Oliveira EA. Predictive factors of chronic kidney disease in primary focal segmental glomerulosclerosis.Pediatric Nephrology2006; 21: 1003-1012

[21]. Gipson DS Chin H, Presler TP, Jennete C, Ferris ME, Massengill S , Gibson K,Thomas DB. Differential risk of remission and ESRD in childhood FSGS. Pediatr Nephrol 2006: 27: 344- 349

[22]. Bhimma R, Coovadia HM, Adhikari M. Nephrotic syndrome in South African children: changing perspectives over 20 years. Pediatr Nephrol 1997;11:429-34. 
[23]. Mantan M, Sriram CS, Hari P, Dinda A, Bagga A. Efficacy of intravenous pulse cyclophosphamide treatment versus combination of intravenous dexamethasone and oral cyclophosphamide treatment in steroid-resistant nephrotic syndrome. Pediatr Nephrol 2008;23:1495-502.

[24]. Plank C, Kalb V, Hinkes B, Hildebrandt F, Gefeller O, Rascher W. Cyclosporin A is superior to cyclophosphamide in children with steroid-resistant nephrotic syndrome: a randomized controlled multicentre trial by the Arbeitsgemeinschaft für Pädiatrische Nephrologie. Pediatr Nephrol 2008;23:1483-93

[25]. Asinobi AO, Gbadegesin RA, Adeyemo AA. The predominance of membranoproliferative glomerulonephritis in childhood nephrotic syndrome in Ibadan, Nigeria. West Afr $J$ Med. 1999; 18(3):203-6.

[26]. Resisistant idiopathic nephrosis with a combination of cyclosporine and prednisone. French Society of Pediatric Nephrology. J Pediatr 1994; 125:981-6.

[27]. A Report of the International Study of Kidney Disease in Children. Nephrotic syndrome in children: Prediction of histopathology from clinical and laboratory characteristics at time of diagnosis. Kidney Int 1978; 13:159-65

[28]. Gargah T,Labessi A,Goucha -Louzir R, Ben Moussa F, Lakhoua MR. Histopathological spectrum of childhood idiopathic steroid resistant nerhrotic syndrome in Tunisia Tunis Med.2011;89(3):258-61.

[29]. Niaudet P. Boyer O.Idiopathic Nephrotic Syndrome in Children . In: Ellis D. Avner, William E. Harmon, Patrick Niaudet and Norishige Yosikawa (eds). Pediatric nephrology, $6^{\text {th }}$ edition, Springer Verlag Berlin Heidelberg. 2009;P:667-702.

[30]. Ejaz I, Khan HI, Javaid BK, Rasool G, Bhatti MT. Histopathological diagnosis and outcome of paediatric nephrotic syndrome. J Coll Physicians Surg Pak 2004;14(4):229-33

[31]. Uszycka-Karcz M, Stolarczyk J, Wrzolkowa T. Mesangial proliferative glomerulonephritis in children. Int J Pediatr Nephrol 1982;3(4): 251-6.

[32]. Hari P, Bagga A, Mantan M. Short term efficacy of intravenous dexamethasone and methylprednisolone therapy in steroid resistant nephrotic syndrome. Indian Pediatr 2004;41:993-1000.

[33]. Bajpai A, Bagga A, Hari P, Dinda A, Srivastava RN. Intravenous cyclophosphamide in steroidresistant nephrotic syndrome. Pediatr Nephrol 2003;18:351-6. 